Review

\title{
Characteristics of Multicomponent Interventions to Treat Childhood Overweight and Obesity in Extremely Cold Climates: A Systematic Review of a Randomized Controlled Trial
}

\author{
Javier Albornoz-Guerrero ${ }^{1}(\mathbb{D})$, Sonia García ${ }^{2}$, Guillermo García Pérez de Sevilla ${ }^{3}$ (D), Igor Cigarroa ${ }^{4}$ (D) \\ and Rafael Zapata-Lamana ${ }^{5, *}$
}

Citation: Albornoz-Guerrero, J.; García, S.; Sevilla, G.G.P.d.; Cigarroa, I.; Zapata-Lamana, R. Characteristics of Multicomponent Interventions to Treat Childhood Overweight and Obesity in Extremely Cold Climates: A Systematic Review of a Randomized Controlled Trial. Int. J. Environ. Res. Public Health 2021, 18, 3098. https://doi.org/10.3390/ ijerph18063098

Academic Editor: Jitse P. van Dijk

Received: 7 January 2021

Accepted: 14 March 2021

Published: 17 March 2021

Publisher's Note: MDPI stays neutral with regard to jurisdictional claims in published maps and institutional affiliations.

Copyright: (c) 2021 by the authors. Licensee MDPI, Basel, Switzerland. This article is an open access article distributed under the terms and conditions of the Creative Commons Attribution (CC BY) license (https:// creativecommons.org/licenses/by/ $4.0 /)$.
1 Departamento de Educación y Humanidades, Universidad de Magallanes, Punta Arenas 6200000, Chile Javier.albornoz@umag.cl

2 Faculty of Sport Sciences, Universidad Europea de Madrid, 28670 Madrid, Spain; sonia.garcia@universidadeuropea.es

3 Faculty of Sports Sciences, Department of Physiotherapy, Universidad Europea de Madrid, 28670 Madrid, Spain; guillermo.garcia@universidadeuropea.es

4 Escuela de Kinesiología, Facultad de Salud, Universidad Santo Tomás, Los Ángeles 4440000, Chile; icigarroa@santotomas.cl

5 Escuela de Educación, Universidad de Concepción, Los Ángeles 4440000, Chile

* Correspondence: rafaelzapata@udec.cl; Tel.: +56-95-838-2133

\begin{abstract}
Aim: To analyze the characteristics of multicomponent interventions to reduce childhood overweight and obesity in territories with an extremely cold climate. Methods: A systematic review was conducted following the PRISMA statement. MEDLINE, PsycNet, SciELO, and grey literature databases were reviewed in the period between 2010 and 2020. Results: 29 articles were included ( $n=4434$ participants; 9.3 years; $56 \%$ women) with an average adherence of $86 \%, 100 \%$ being the highest adherence, for the physical activity and nutrition interventions. The primary variables studied were BMI, BMI Z-score BMI-SDS and, additionally, the secondary variables studied were nutritional status and physical and mental health. In $72 \%$ of the interventions presented, positive effects were seen on the reduction of BMI, including in parents and their children. The interventions were carried out mainly by nutritionists in health centers. The duration of the 29 interventions was $\leq 6$ months and $\geq 12$ months, in $59 \%$ and $41 \%$ of the studies, respectively. $57 \%$ of the studies reported postintervention results. $86 \%$ of the interventions included a physical activity component, $80 \%$ included a nutrition component, $66 \%$ included a behavioral therapy component and $55 \%$ included an education component. Concerning the effects of the intervention on the primary outcome, in interventions with a duration equal to or less than six months, the most effective interventions included recreational activities, education, and nutritional programs. In interventions lasting 12 months or more, the most effective interventions included physical activity recommendations, nutritional and physical exercise programs, and cooking classes. Conclusions: This systematic review analyzed the effectiveness of, and characterized, multicomponent interventions lasting for 6 and 12 months, aiming to treat childhood obesity in extremely cold climates. The most frequently used units of measurement were also analyzed and summarized. Evidence derived from RCT. These results can be useful for designing future interventions to treat childhood obesity in territories with an extremely cold climate.
\end{abstract}

Keywords: pediatric obesity; obesity management; treatment; extremely cold climate

\section{Introduction}

The World Health Organization (WHO) has consistently reported that overweight and obesity are causing a significant deterioration in the health of the world's population [1] These conditions have been linked for decades to the development of diseases such as 
insulin resistance, type 2 diabetes mellitus, high blood pressure, dyslipidemia, and fatty liver disease [2-4]. More recently, obesity has been linked to various types of cancer [5], and it has been estimated that $14 \%$ and $20 \%$ of deaths in men and women, respectively, can be attributed to obesity [6].

Regarding the global prevalence of obesity, it has almost tripled. Specifically, in 2019 the estimation was that 38.2 million children under the age of five were overweight or obese. This is a problem in high-, middle- and low-income countries, particularly in urban settings [7]. Besides, the prevalence of overweight and obesity among children and adolescents aged 5 to 19 years has increased dramatically, similarly among boys and girls [7].

The consequences of childhood obesity are increased school absences and doctor visits [8], so childhood obesity is not simply a risk factor for disease in adulthood, as obese children may experience more illness during childhood [9]. In this regard, early detection and treatment of obesity in children may be the best approach to prevent future increases in morbidity, as well as increases in the health care costs that are likely to occur as overweight and obese children grow older $[10,11]$.

Treatment strategies for childhood obesity have been carried out in multiple ways. Modifying the obesogenic environment and ensuring the acquisition of healthy lifestyle habits has been suggested for more than a decade [12]. Interventions with the family and school are considered as an important strategy against obesity [13]. These strategies consist of nutrition, physical activity, or psychosocial support, and when used in combination they are called multicomponent interventions [14,15].

It has been reported that there is an association between extreme cold weather and childhood overweight or obesity. Thus, it has been shown that cold environments favor the development of obesity since it could influence hormones related to hunger, increasing the appetite towards excessive intake, and promote inactivity [16,17]. Furthermore, this type of climate causes multiple systemic adaptations, such as sympathetic thermogenesis in brown adipose tissue, post-shiver thermogenesis in skeletal muscle, increased production of expired carbon dioxide due to increased metabolic activity, and tachycardia [18]. Similarly, exposure to cold temperatures alters hormonal production, observing an increase in ghrelin and cortisol, which have been associated with an increase in appetite, and facilitating mechanisms of lipid storage [19].

Among the coldest countries in the world are Russia, Canada, USA (north), Iceland, Finland, Estonia, Norway, Sweden, Denmark, Latvia, France, and New Zealand (south) [20]. Scotland in the United Kingdom, the extreme south of Argentina and Chile [21], some areas of the island of Tasmania in Australia, part of the Atlantic coast of Norway, and part of the European islands in the North Atlantic Ocean belong to the subpolar oceanic climate [22]. In this climate, months with an average temperature above $10^{\circ} \mathrm{C}$. are less than four per year.

In Punta Arenas, Chile, winds of 80 miles per hour are common during the southern hemisphere summer. The temperature varies around an average of $6.5^{\circ} \mathrm{C}$, with the lowest temperature of $-16.4^{\circ} \mathrm{C}$ in Winter, June and July, and the highest of $29.9^{\circ} \mathrm{C}$ in summer, January and February [23].

The collected data on extreme cold weather are relevant for designing intervention strategies aimed at reducing overweight or obesity in children in these climates. To date, no systematic reviews have been reported that specify the characteristics of the interventions in children with overweight and obesity in territories with extremely cold climate characteristics.

Therefore, the objective of this review is to analyze the characteristics of multicomponent interventions aimed at reducing overweight and obesity in children in territories with an extremely cold climate.

\section{Methods}

This systematic review was carried out in accordance with the standards established by the PRISMA declaration [24]. 


\subsection{Search Strategy to Identify Studies}

We reviewed the MEDLINE databases using PubMed, PsycNet, SciELO, and grey literature. The objective was to identify studies that carried out interventions for the treatment of overweight and obesity in children in extremely cold climates. The search covered the period from January 2010 to January 2020 taking as reference the Global Action Plan for the Prevention and Control of NCDs in the Americas. For this search, we used The MeSH terms: "Therapy", "Therapeutics", “Rehabilitation", "Obesity", “Overweight" and "Child". The search strategy followed the Peer Review of Electronic Search Strategies (PRESS) [25]. The search terms were: (Therapy OR Therapeutics OR Rehabilitation) AND (Obesity OR Overweight) AND (Child), adapted to each database applying the following filters: period (January 2010 to October 2020), type of article (Randomized Controlled Trial), age (6-12 years) and country (Russia, Canada, United States, Iceland, Finland, Estonia, Norway, Sweden, Denmark, Latvia, France, New Zealand, Scotland, United Kingdom, Argentina, Chile, Faroe Islands, and Iceland).

\subsection{Study Selection and Inclusion Criteria}

Studies that met the following inclusion criteria were selected: (a) Country: interventions carried out in countries with extremely cold climates (Russia, Canada, USA, Iceland, Finland, Estonia, Norway, Sweden, Denmark, Latvia, France, New Zealand, Scotland, United Kingdom, Argentina, Chile, Faroe Islands, and Iceland); (b) Sample: boys and girls between 6 and 12 years old; (c) Methodological Design: randomized controlled clinical trial; (d) Period: between 2010 and 2020. Exclusion criteria were: reviews, editorial documents, protocols, and doctoral thesis (Table 1).

Table 1. Eligibility criteria of the studies.

\begin{tabular}{ll}
\hline \multicolumn{1}{c}{ Criteria } & \multicolumn{1}{c}{ Description } \\
\hline $\begin{array}{l}\text { (1) } \begin{array}{l}\text { Type of intervention: } \\
\text { multi-component intervention } \\
\text { Duration }\end{array} \\
\text { (2) Participants }\end{array}$ & $\begin{array}{l}\text { (a) } \begin{array}{l}\text { Education, behavioral therapy, nutrition therapy, and physical } \\
\text { activity or physical exercise } \\
\text { To present complementary interventions (more than one) }\end{array} \\
\text { (c) At least four weeks }\end{array}$ \\
& (a) Overweight or obese; boys and girls; aged 6 to 12 years \\
(3) Study variables for intervention effects & (a) Physical health: aerobic fitness, muscular strength, flexibility, \\
& (b) Mental health: depression, mood, self-esteem, health-related \\
(4) Type of article & (c) Cognitive skills: memory, perception, language, attention, \\
\hline (5) Country of origin of the population & (a) Original article with experimental design and random assignment. \\
\hline
\end{tabular}

\subsection{Data Extraction}

First, we used the Mendeley tool to look for duplicates. As no duplicates were found, then the articles that met the inclusion criteria were selected. When decisions could not be made considering only the title and abstract of the article, the full text was retrieved (Figure 1). We used a standardized questionnaire to extract the data from the included articles to synthesize the evidence. The information extracted included: (a) general characteristics of the studies and the participants (author, year, country, sample size, adherence, reasons for withdrawal, recruitment, age, sex, inclusion criteria, and place of intervention) (b) main characteristics of the interventions; (c) characteristics of the interventions according to the component addressed; (d) main variables assessed (physical health and mental health); (e) main assessment instruments used. 


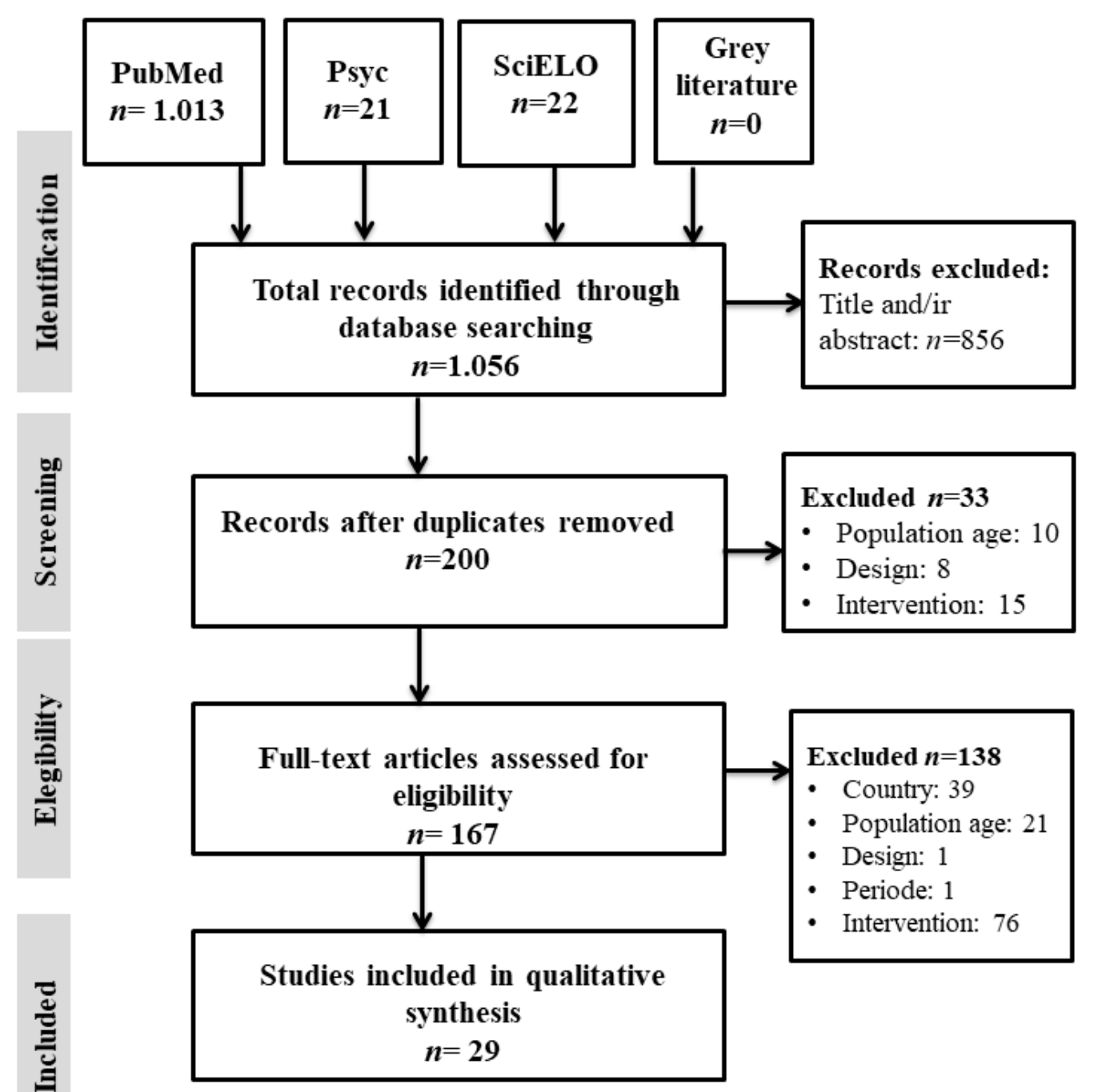

Figure 1. PRISMA flow chart.

\subsection{Risk of Bias Tool}

To assess the methodological quality of the studies included in this review, we used the "Cochrane Handbook of Systematic Reviews of Interventions" [26], evaluating the risk of bias in each of the proposed items: (a) Selection bias, (b) Performance bias, (c) Detection bias, (d) Attrition bias and (e) Reporting bias. The only item that was not considered was "Other biases". The results of this analysis are presented, grouping all the studies analyzed (Figure 2).

\subsection{Data Synthesis Strategy}

The main information of the included studies is presented in summary tables and figures. In the discussion, the most relevant methodological and applicability aspects are analyzed and some suggestions for future research are given. 


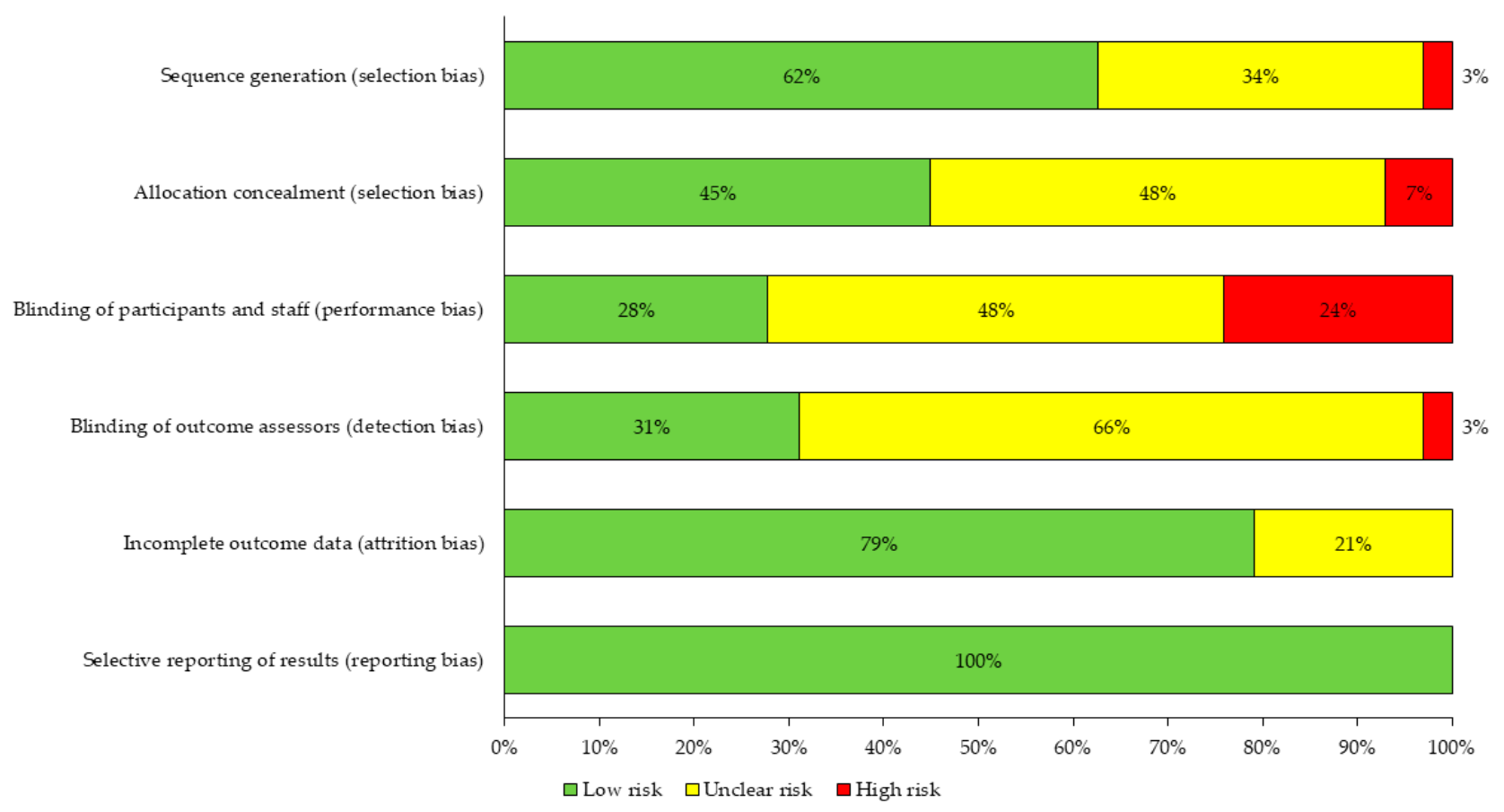

Figure 2. Risk of bias assessment.

\section{Results}

\subsection{Search Outcome}

Figure 1 shows the flow chart made following the PRISMA Statement. We identified 1056 potential studies on the treatment of childhood overweight and obesity in countries with extremely cold climates. After the exclusion of the duplicates in the databases, the screening and eligibility criteria were applied. Finally, 29 articles were included for data synthesis in this review [27-55].

\subsection{Characteristics of the Studies Analyzed}

29 articles were included in this review, whose interventions were carried out in the following countries considered as extreme cold climate zones: Sweden, Canada, Denmark, United States, Iceland, Germany, Norway, Switzerland, England, Finland, Holland, and China. Considering all the studies, the total number of subjects at baseline was 4434 , with an average adherence of $86 \%$. The adherence to the programs, depending on the type of the intervention, was: (1) Physical activity and nutrition: 100\%; (2) education: 93\%; (3) behavioral and education: 93\%; (4) physical activity and education and nutrition: $87 \%$; (5) behavioral and nutrition: $86 \%$; (6) physical activity and behavioral: $86 \%$; (7) physical activity and behavioral and education and nutrition: $84 \%$; (8) physical activity and behavioral and nutrition: $81 \%$. Of these studies, $93 \%$ reported losses in their sample, the main reasons being categorized as follows: lack of time (10\%), personal reasons $(24 \%)$, attendance $(41 \%)$, health $(20 \%)$, not meeting criteria during the development of the intervention $(17 \%)$, did not wish to continue (27\%) and unspecified (34\%). $58 \%$ of the studies recruited children from health centers, $27 \%$ from educational centers, and $51 \%$ from the community. The mean age was 9.3 years. Concerning gender distribution, $56 \%$ were women and $44 \%$ men. Regarding the prevalence of diseases, only two studies detailed this information: one included a child with asthma, and the other only healthy children. The main inclusion criterion $(90 \%)$ was the BMI value corresponding to overweight or obesity, while in 3\% of the studies it was the value of weight for height and $7 \%$ did not specify this information. $51 \%$ of the interventions were carried out in health centers, $13 \%$ in educational centers, $13 \%$ in university centers, and $13 \%$ in community centers. Of these studies, $13 \%$ did not specify this information (Table 2). 


\subsection{Risk of Bias Assessment}

The risk of bias analysis revealed that the distribution of biases classified as "low risk" or "unclear risk" was similar, except for detection bias, in which $66 \%$ of the studies presented "unclear risk", and reporting bias, in which $100 \%$ of the studies presented "low risk". Among the four types of bias, studies classified as "high risk" were only for "performance bias", where more than $10 \%$ (22\%) of the studies presented "high risk" (Figure 2).

\subsection{Main Characteristics of the Interventions}

The studies presented as main result six variables related to childhood overweight and obesity: 38\% reported BMI z-score, 34\% reported BMI-SDS (standard deviation), $24 \%$ considered BMI $(\mathrm{kg} / \mathrm{m} 2)$ and $10 \%$ considered other variables, these being the percentage of body fat, body weight according to height and BMI-p (percentile). Regarding the main post-intervention result, $72 \%$ of the interventions presented significant changes, while $28 \%$ did not present significant post-intervention changes. Only nine studies analyzed the maintenance of this effect over time, obtaining statistically significant maintenance in $77 \%$ of cases. One of the inclusion criteria of $38 \%$ of the studies was that at least one of the parents was overweight or obese. In relation to the subjects who underwent the intervention, $4 \%$ included only parents, $6 \%$ only children, $52 \%$ included parents and children, and $34 \%$ included the entire family. In $59 \%$ of the studies, the duration of the intervention was equal to or less than 6 months, and in $41 \%$ it was equal to or greater than 12 months. $57 \%$ of the studies presented follow-up of post-intervention results. Of these, $43 \%$ followed up for a period equal to or less than 6 months, while $57 \%$ followed up for a period equal to or greater than 12 months. Regarding the professionals who participated in the interventions, $52 \%$ were nutritionists, $34 \%$ qualified professionals in exercise prescription (physiotherapists, physical education teachers, and personal trainers), $32 \%$ doctors, $27 \%$ psychologists, $27 \%$ other types of professional (interventionists, counselors or facilitators), $23 \%$ included a nurse, $2 \%$ a social worker and $9 \%$ did not specify this information. The interventions were based on four components: (1) physical activity, (2) education, (3) behavioral therapy, (4) and nutrition. The physical activity component was included in $86 \%$ of the interventions, being implemented in $55 \%$ of cases as recommendations (general exercise recommendations, promotion of an active life, and reduction of time spent in sedentary behaviors), in $16 \%$ of cases as physical exercise programs (structured training program including mainly aerobic exercise, circuit training, and spinning), and in $23 \%$ of cases as recreational activities (mainly games). Of the interventions. 55\% included an education component, which was implemented mainly as healthy lifestyle recommendations focused on health promotion. Regarding behavioral therapy, $66 \%$ of the interventions included this component through cognitive-behavioral strategies: stimulus control, self-monitoring, coping strategies, dealing with problems, positive reinforcement, planning, goal setting, behavior skills, and parenting skills. Finally, $80 \%$ of the interventions included a nutrition component, which was implemented in $45 \%$ of cases as recommendations focused on healthy eating (such as increasing the intake of water, fruits, and vegetables and reducing the intake of high-calorie foods), in $34 \%$ of the cases as food plans using mainly the "traffic light system", and in $6 \%$ of cases healthy eating workshops were included (Table 3). 
Table 2. Characteristics of the studies analyzed in multicomponent interventions in extremely cold climates.

\begin{tabular}{|c|c|c|c|c|c|c|c|c|c|c|c|c|c|c|c|c|c|c|c|c|c|c|c|c|}
\hline \multirow[t]{3}{*}{ Ref. } & \multirow[t]{3}{*}{ Main Author, Year, Contry } & \multirow[t]{3}{*}{ Sample Size } & \multirow{3}{*}{$\begin{array}{c}\text { Adherence } \\
\%\end{array}$} & \multirow[b]{3}{*}{ LT } & \multicolumn{5}{|c|}{ Reason for Exclusion } & \multicolumn{4}{|c|}{ Recruiting } & \multirow{3}{*}{$\begin{array}{l}\text { Age } \\
\text { mean }\end{array}$} & \multicolumn{2}{|c|}{ Sex } & \multicolumn{3}{|c|}{ Inclusion Criteria } & \multicolumn{5}{|c|}{ Place of the Intervention } \\
\hline & & & & & & & & & & & & & & & \& & $0^{\pi}$ & & & & & & & & \\
\hline & & & & & PR & AT & NS & HE & DNMC & DWC & HC & EC & COM & & $\%$ & $\%$ & BMI & W/H & NS & HC & EC & UC & $\mathrm{CC}$ & NS \\
\hline [27] & Mårild S. (2013), Sweden & 265 & 93 & - & - & - & 1 & - & - & - & - & 1 & - & 11 & 58 & 42 & - & - & 1 & 1 & - & - & - & - \\
\hline [28] & Cohen T. (2016) Canada & 78 & 93 & 1 & 1 & - & - & - & - & - & 1 & 1 & 1 & 8 & 58 & 42 & 1 & - & - & - & - & 1 & - & - \\
\hline [29] & Traberg C. (2016) Denmark & 115 & 75 & - & - & - & 1 & 1 & 1 & 1 & - & 1 & - & 12 & 45 & 55 & 1 & - & - & - & - & - & 1 & - \\
\hline [30] & Saelens B. (2013) USA & 89 & 80 & - & - & 1 & - & - & - & - & 1 & - & 1 & 9 & 67 & 33 & 1 & - & - & - & - & _ & - & 1 \\
\hline [31] & Gunnarsdottir T. (2014) Iceland & 16 & 81 & - & 1 & 1 & - & - & - & 1 & 1 & - & - & 10 & 68 & 32 & 1 & - & - & 1 & - & - & - & - \\
\hline [32] & Harder-Lauridsen N. (2014) Denmark & 38 & 92 & - & 1 & - & - & - & 1 & - & - & 1 & - & 8 & 80 & 20 & 1 & - & - & - & 1 & - & 1 & - \\
\hline [33] & Reinehr T. (2010) Germany & 66 & 91 & - & - & - & 1 & - & - & - & 1 & - & 1 & 11 & 58 & 42 & 1 & - & - & - & 1 & - & - & - \\
\hline [34] & Benestad B. (2017) Norway & 94 & 73 & - & 1 & 1 & - & - & 1 & 1 & 1 & - & - & 10 & 50 & 50 & 1 & - & - & 1 & - & - & - & - \\
\hline [35] & Danielsson P. (2016) Sweden & 589 & 100 & - & - & - & - & - & - & - & 1 & - & - & 9 & 46 & 54 & 1 & - & - & 1 & - & - & - & - \\
\hline [36] & Epstein L. (2014) USA & 101 & 66 & - & - & - & 1 & - & - & - & - & - & 1 & 11 & 60 & 40 & 1 & - & - & - & - & 1 & - & - \\
\hline [37] & Wilfley D. (2017) USA & 172 & 93 & - & - & - & 1 & - & - & - & - & - & 1 & 9 & 61 & 39 & 1 & - & - & - & - & 1 & - & - \\
\hline [38] & Larsen L. (2015) Denmark & 80 & 93 & - & - & - & 1 & - & - & - & - & - & 1 & 6 & 64 & 36 & - & - & 1 & - & - & - & - & 1 \\
\hline [39] & Farpour-Lambert N. (2019) Switzerland & 74 & 89 & - & - & - & - & 1 & - & 1 & 1 & - & - & 9 & 51 & 49 & 1 & - & - & 1 & - & - & - & - \\
\hline [40] & Wylie-Rosett J. (2018) USA & 366 & 73 & - & - & 1 & - & - & 1 & 1 & 1 & - & - & 9 & 52 & 48 & 1 & - & - & 1 & - & - & - & - \\
\hline [41] & Warschburger P. (2016) Germany & 685 & 76 & - & - & - & 1 & - & 1 & - & 1 & - & - & 11 & 52 & 48 & 1 & - & - & 1 & - & - & - & - \\
\hline [42] & Christison A. (2016) USA & 84 & 95 & - & - & 1 & - & - & - & - & 1 & - & 1 & 10 & 54 & 46 & 1 & - & - & - & - & - & 1 & - \\
\hline [43] & Croker H. (2012) England & 72 & 79 & - & - & 1 & - & 1 & - & 1 & 1 & 1 & 1 & 10 & 70 & 30 & 1 & - & - & 1 & - & - & - & - \\
\hline [44] & Kokkvoll A. (2015) Norway & 97 & 85 & - & 1 & 1 & - & 1 & - & - & - & - & 1 & 10 & 54 & 46 & 1 & - & - & 1 & - & - & - & - \\
\hline [46] & Kalavainen M. (2012) Finland & 70 & 97 & - & - & - & - & - & - & - & - & - & 1 & 8 & 60 & 40 & - & 1 & - & 1 & - & - & - & - \\
\hline [47] & Njardvik U. (2018) Iceland & 90 & 67 & - & - & - & 1 & - & - & - & - & 1 & - & 11 & 45 & 55 & 1 & - & - & 1 & - & - & - & - \\
\hline [48] & Gerards S. (2015) The Netherlands & 86 & 85 & 1 & 1 & 1 & - & - & - & - & 1 & - & 1 & 7 & 55 & 45 & 1 & - & - & 1 & - & - & - & - \\
\hline [49] & Boutelle K. (2011) USA & 80 & 63 & 1 & 1 & - & - & 1 & - & 1 & 1 & - & 1 & 10 & 60 & 40 & 1 & - & - & - & - & 1 & - & - \\
\hline [50] & Robertson W. (2017) England & 105 & 84 & - & - & 1 & - & 1 & - & 1 & 1 & 1 & 1 & 9 & 65 & 35 & 1 & - & - & - & 1 & - & 1 & - \\
\hline [51] & Ming Hao M. (2019) China & 229 & 100 & - & - & - & - & - & - & - & - & 1 & - & 10 & 45 & 55 & 1 & - & - & - & 1 & - & - & - \\
\hline [52] & Steven D. (2014) USA & 72 & 97 & - & - & 1 & - & - & - & - & 1 & - & - & 6 & 36 & 64 & 1 & - & - & 1 & - & - & - & - \\
\hline [53] & de Niet J. (2012) Nederlands & 144 & 98 & - & - & - & 1 & - & - & - & 1 & - & - & 10 & 64 & 36 & 1 & - & - & 1 & - & - & - & - \\
\hline [54] & Sherwood N. (2018) USA & 421 & 86 & - & - & 1 & - & - & - & - & 1 & - & - & 6 & 50 & 50 & 1 & - & - & 1 & - & - & - & - \\
\hline [55] & Saelens B. (2017) USA & 29 & 82 & - & - & - & 1 & - & - & - & - & - & 1 & 10 & 59 & 41 & 1 & - & - & - & - & - & - & 1 \\
\hline
\end{tabular}

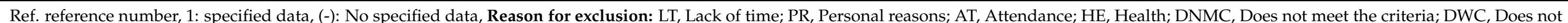

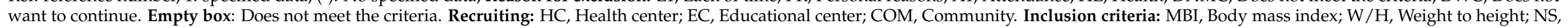
No specified. Intervention place: HC, Health center; EC, Educational center; UC, University center; CC, Community center. 
Table 3. Main characteristics of multicomponent interventions according to component addressed.

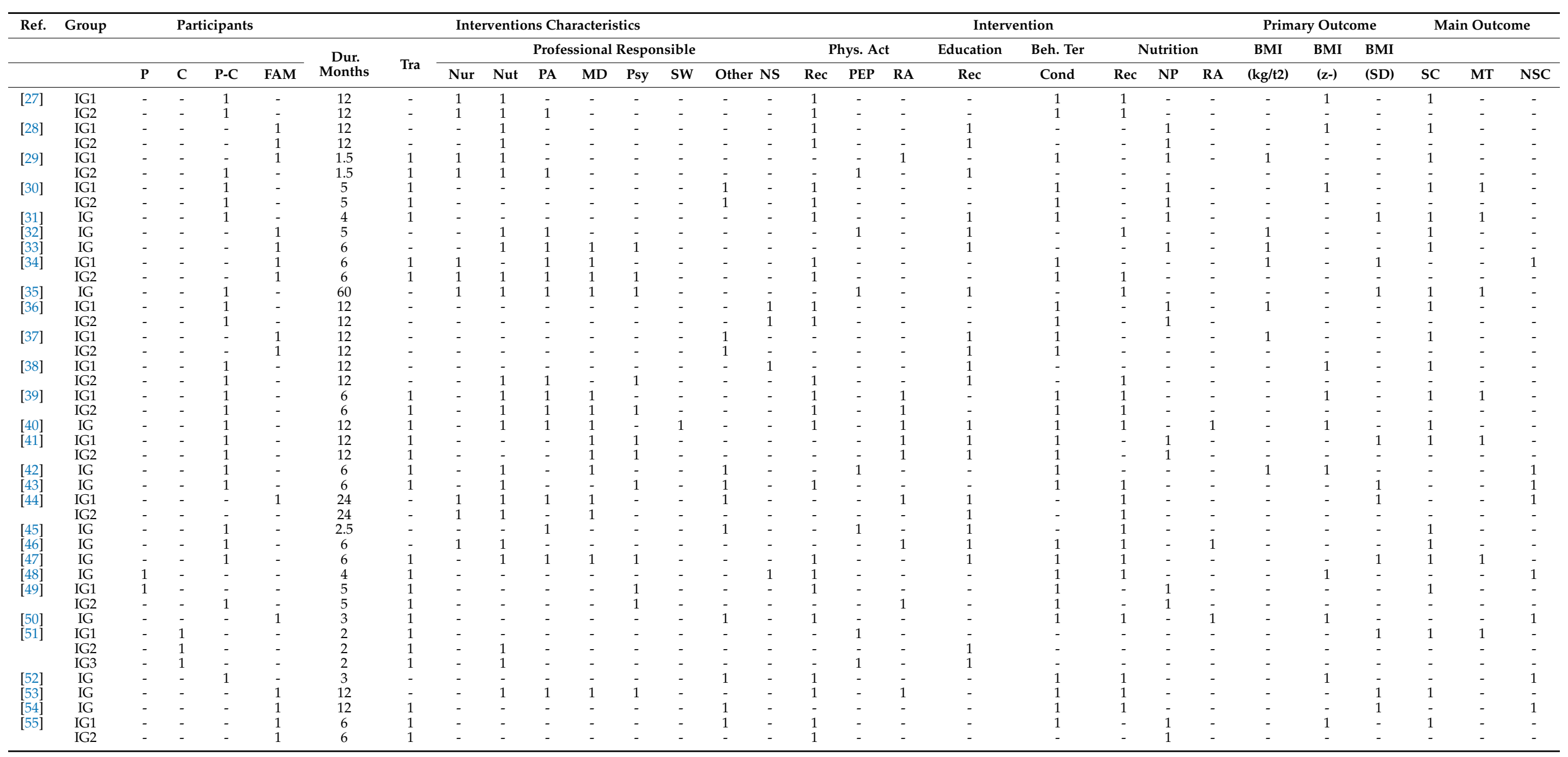

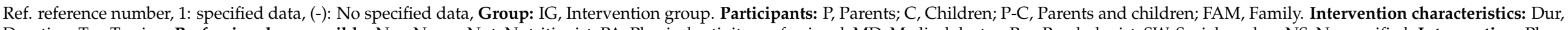

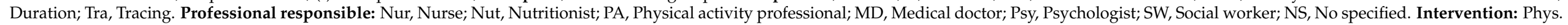

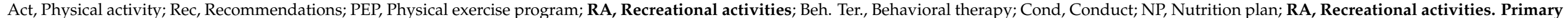

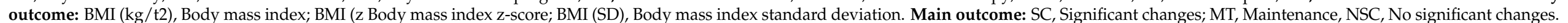




\subsection{Effects of the Interventions on the Primary Outcome According to the Duration of the Intervention}

Duration equal to or less than six months: Considering all types of interventions, $77 \%$ obtained significant effects for the primary outcome. All the interventions that included the physical activity component showed significant effects on the primary outcome with the recreational activities modality, while with the recommendations modality they obtained significant effects in $59 \%$ of cases, and $83 \%$ of cases using the physical exercise program modality. All the interventions that included education had significant effects on the primary outcome, whereas those that included behavioral therapy had significant effects in $65 \%$ of cases. Finally, $100 \%$ of the interventions that included a nutrition component showed significant effects on the primary outcome when using the diet program modality, $63 \%$ with the recommendation's modality, and 50\% when using the healthy cooking workshop modality. Furthermore, considering that all the interventions included at least two components, they all presented significant effects when they included the physical activity component in the form of recreational activities. However, the interventions that combined physical activity (recommendations approach), behavioral therapy, and nutrition component (recommendations approach) only presented significant effects when they also included the education component,

Duration equal or more than twelve months: of the interventions, $89 \%$ had significant effects on the primary outcome. $67 \%$ of interventions that included a physical activity component presented significant effects with the recreational activities modality, $100 \%$ with the recommendations modality, and $100 \%$ with the physical exercise program modality. Regarding interventions that included education, $92 \%$ presented significant effects on the result. The interventions that included behavioral therapy had significant effects in $91 \%$ of cases. Finally, $100 \%$ of the interventions that included a nutrition component showed significant effects on the primary outcome with the diet program modality, $75 \%$ with the recommendations modality, and 100\% with the healthy cooking workshop modality. Furthermore, only two interventions (11\%) did not present significant effects, having in common that both included the nutrition component in the modality of recommendations (Table 4).

\subsection{Variables Studied in the Articles}

The variables studied in the different studies were grouped into three categories: nutritional status, physical and health condition, and psychological variables.

\subsubsection{Nutritional Status}

This category was considered in $100 \%$ of the studies and included eight variables: BMI z-score ( $86 \%$ of studies), BMI (79\%), waist circumference ( $44 \%)$, body composition (mainly fat mass and lean mass; $34 \%$ ), waist-to-height ratio $(14 \%)$, skinfold (10\%), hip circumference $(6 \%)$ and neck circumference $(3 \%)$ (Figure $3 a)$. 
Table 4. Statistically significant effects of the interventions lasting 6, and 12 months.

\begin{tabular}{|c|c|c|c|c|c|c|c|c|}
\hline \multirow[b]{3}{*}{$\begin{array}{l}\text { Statistically significant change over } \\
\text { the primary outcomes }\end{array}$} & \multicolumn{8}{|c|}{ Duration of the Intervention: 6 and 12 Months } \\
\hline & \multicolumn{3}{|c|}{ Physical Activity } & \multirow[t]{2}{*}{ Education } & \multirow[t]{2}{*}{$\begin{array}{c}\text { Behavioral } \\
\text { Therapy }\end{array}$} & \multicolumn{3}{|c|}{ Nutrition } \\
\hline & $\begin{array}{l}\text { Recreational } \\
\text { activities }\end{array}$ & Recommendations & $\begin{array}{c}\text { Physical exercise } \\
\text { program }\end{array}$ & & & $\begin{array}{l}\text { Nutrition } \\
\text { program }\end{array}$ & Recommendations & Cooking class \\
\hline$\leq 6$ months & $100 \%$ & $59 \%$ & $83 \%$ & $100 \%$ & $65 \%$ & $100 \%$ & $63 \%$ & $50 \%$ \\
\hline$\geq 12$ months & $67 \%$ & $100 \%$ & $100 \%$ & $92 \%$ & $91 \%$ & $100 \%$ & $75 \%$ & $100 \%$ \\
\hline
\end{tabular}



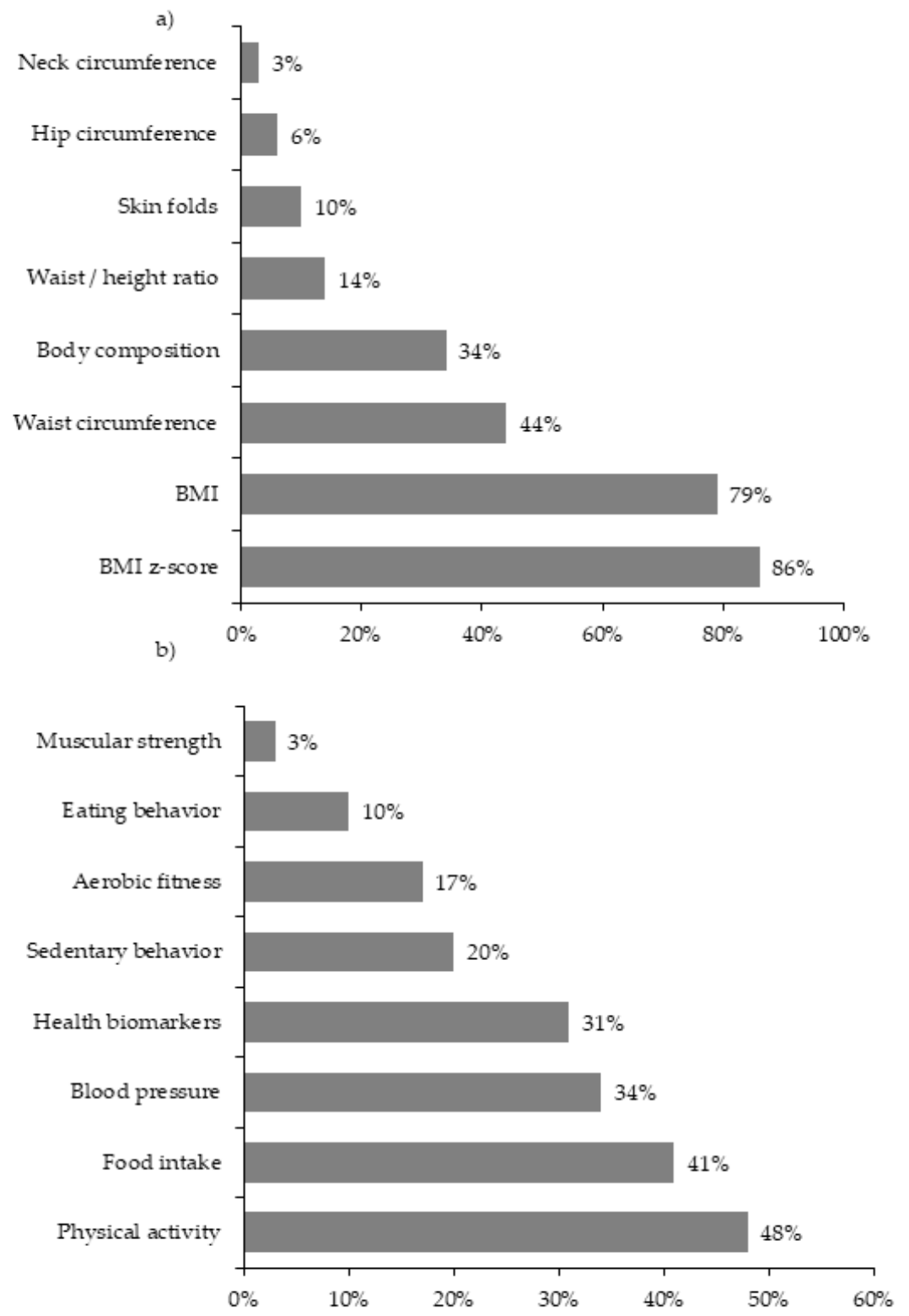

c)

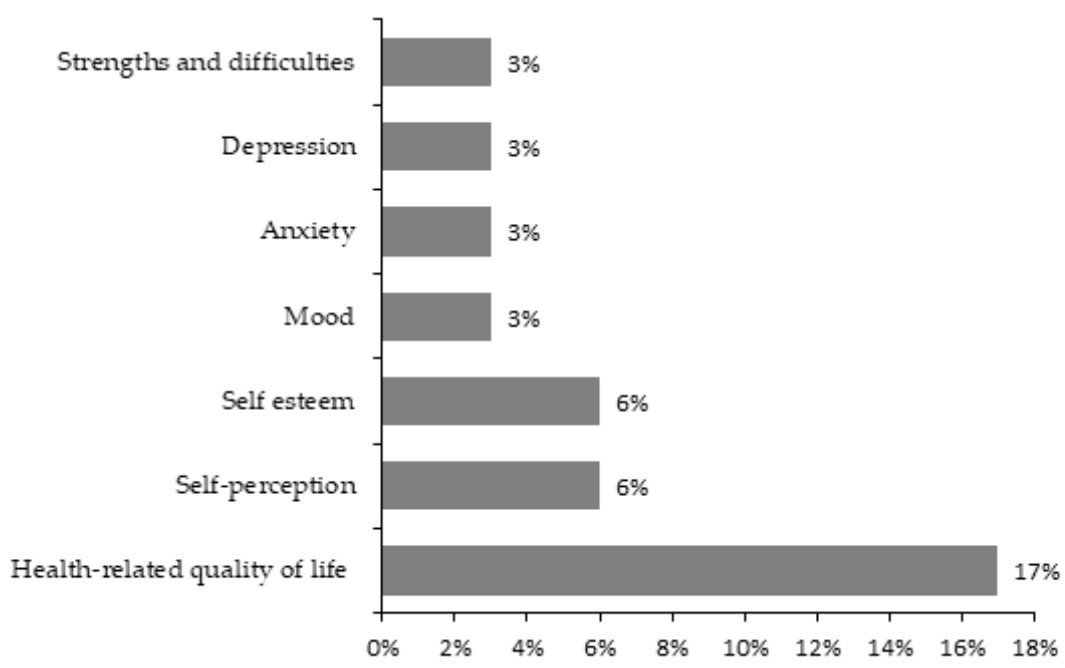

Figure 3. Variables of (a) nutritional status, (b) physical and health condition, and (c) psychological health. 


\subsubsection{Physical and Health Condition}

This category was considered in $76 \%$ of the studies and included eight variables: physical activity level ( $48 \%$ of studies), food intake $(41 \%)$, blood pressure $(34 \%)$, health biomarkers (31\%), sedentary behavior (20\%), aerobic fitness (17\%), eating behavior $(10 \%)$, muscular strength (3\%) (Figure 3b).

\subsubsection{Mental Health}

This category was considered in $24 \%$ of the studies and included seven variables: health-related quality of life (17\% of studies), self-perception $(6 \%)$, self-esteem $(6 \%)$, mood $(3 \%)$, anxiety $(3 \%)$, depression $(3 \%)$, and strengths and difficulties perceived by parents $(3 \%)$ (Figure 3c).

\subsection{Assessment Instruments}

The instruments used in the studies were grouped into three categories: nutritional status, physical and health condition, and psychological variables.

\subsubsection{Nutritional Status}

To assess these variables, six instruments were used: tape measure ( $34 \%$ of studies), anthropometry measurement $(17 \%)$, bio impedance measurement $(13 \%)$, dual-energy $x-$ ray absorptiometry (DXA) $(13 \%)$, caliper $(6 \%)$, and the three-component model of body composition (3\%) (Figure 4a).

\subsubsection{Physical and Health Condition}

To assess these variables, 20 instruments were used, and were sub-grouped into four categories:

Nutrition: to assess this category, the instruments used were food frequency questionnaire (17\% of the studies), 3-day diet recall form (10\%), 24 h-dietary recall (3\%), Block Kids questionnaire (3\%), Dutch eating behavior questionnaire for children (DEBQ-C) (3\%), The Family Eating and Activity Habits questionnaire (FEAH) (3\%), Day in the life questionnaire (DiLQ) (3\%) and 2-day nutritional dietary record (3\%) (Figure $4 b$ ).

Level of physical activity and sedentary behavior: to assess this category, the instruments used were non-validated questionnaire for dietary, physical activity and sedentary behaviors (33\% of studies), accelerometers $(13 \%)$, pedometer $(6 \%)$, Physical activity questionnaire for children (PAQ-Q) (6\%), Leisure Score Index (LSI) (3\%) (Figure 4c).

Physical condition: to assess this category, the instruments used were walking test (6\% of studies), handgrip strength test (3\%), ergo-spirometry test $(3 \%)$, jumping test (3\%) (Figure 4d).

Cardiovascular risk: $31 \%$ of the studies took blood samples, while $13 \%$ measured blood pressure with a manual blood pressure cuff, and $20 \%$ with an automatic sphygmomanometer (Figure 4e).

\subsubsection{Psychological Variables}

Ten instruments were used to assess these variables, and were sub-grouped into two categories:

Psychological health: to assess this category, $6 \%$ of studies used the self-perceptions profile questionnaire for children (SPPC), 6\% the children's depression scale (CDS), $6 \%$ the questionnaire of strengths and difficulties of the child reported by the parents (SDQ), 3\% used the child and youth physical self-perception profile questionnaire (CY-PSPP), $3 \%$ the scale of intrinsic versus extrinsic orientation in the classroom, and $3 \%$ the multidimensional anxiety scale for children (MASC) (Figure 4f).

Health-related quality of life: of the studies, $6 \%$ used the pediatric quality of life questionnaire (PedsQL), 3\% the child health questionnaire, Dutch version (CHQ-PF50) and $3 \%$ the quality of life questionnaire for children between 7 and 13 years old (KID-KINDL-R) (Figure 4g). 


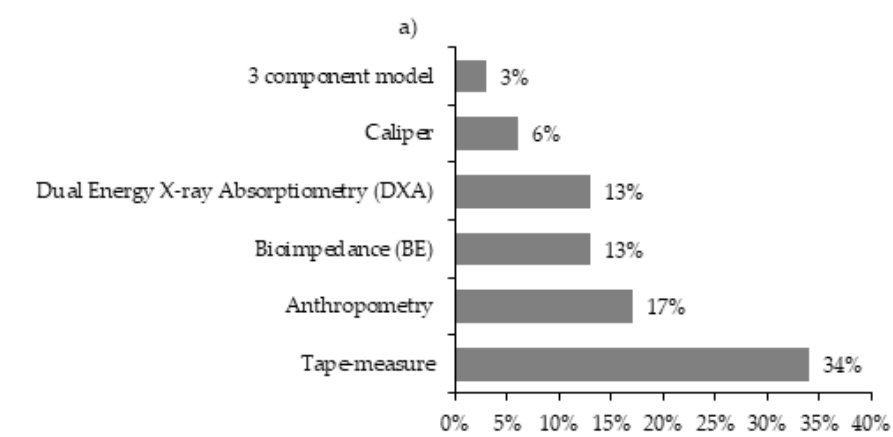

b)
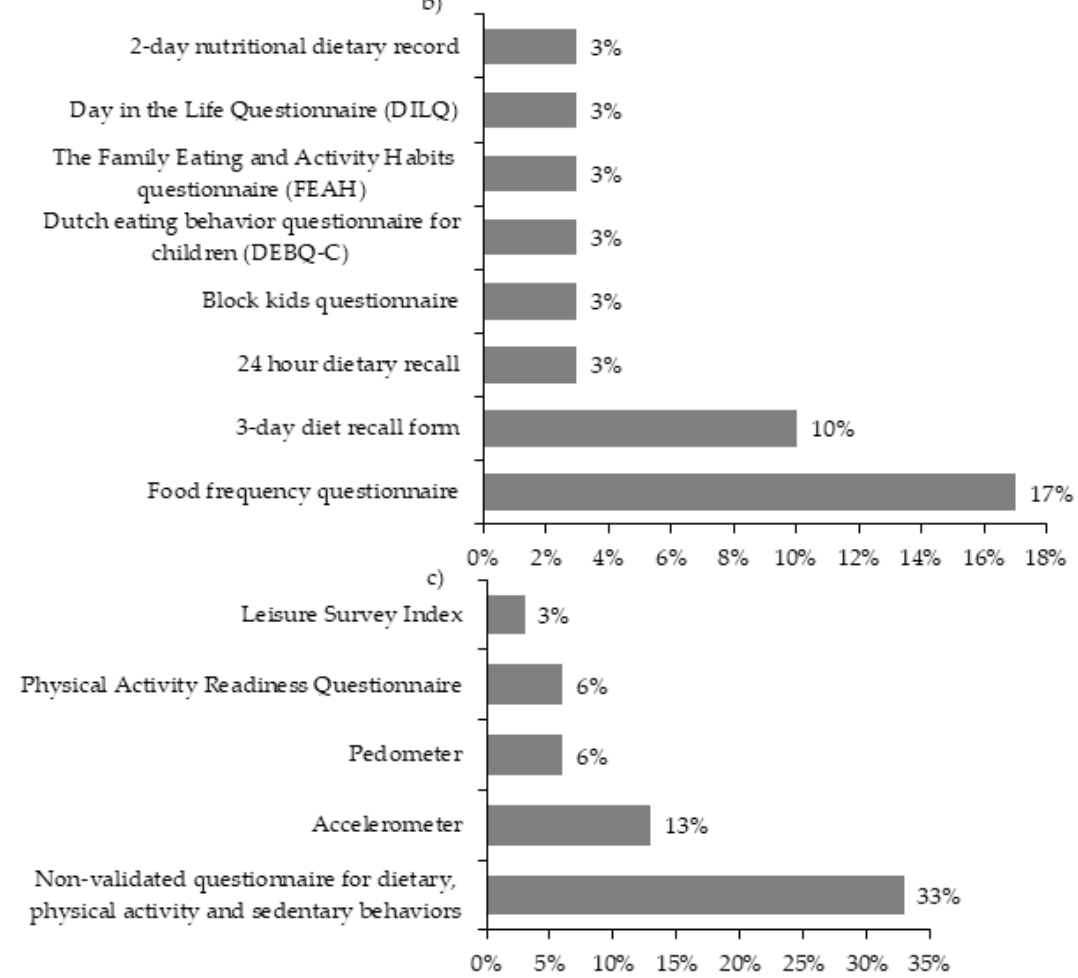

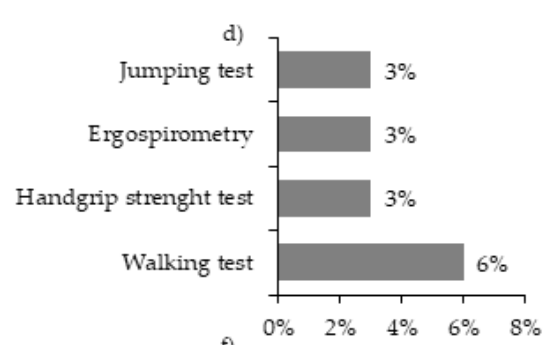

f)

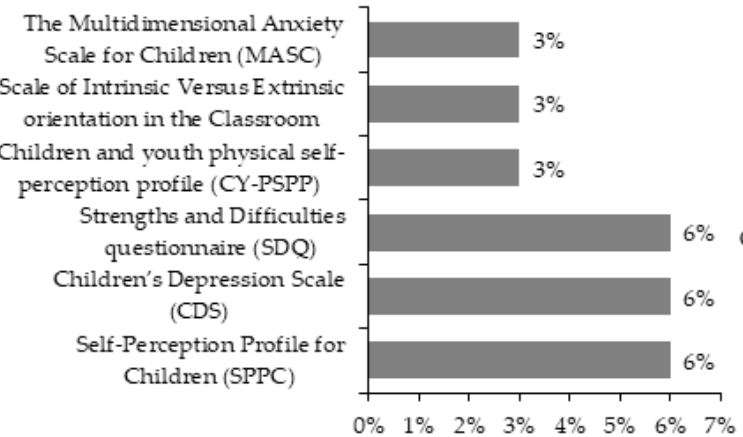

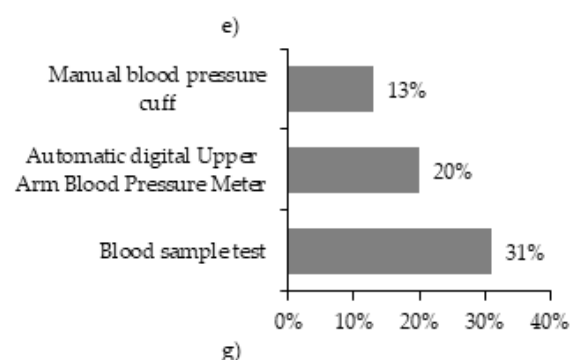

g)

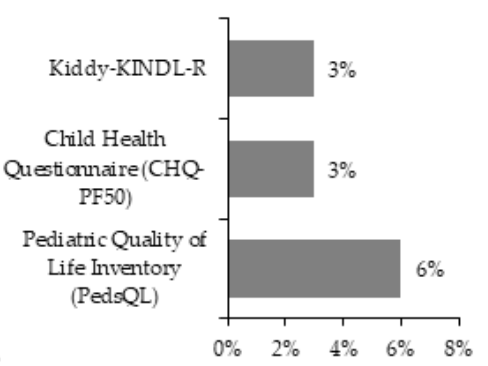

Figure 4. Instruments for the assessment of (a) nutritional status, physical and health condition; (b) nutrition, (c) level of physical activity and sedentary behavior, (d) physical condition, (e) cardiovascular risk, psychological variables; (f) health and $(\mathrm{g})$ health-related quality of life. 


\section{Discussion}

The main finding of this review is that interventions that are effective for the management of childhood overweight and obesity are those that combine the components of physical activity, diet, education, and behavioral therapy, and that involve children and parents as participants in the intervention. Specifically, the most effective interventions with a duration equal to or less than six months included recreational activities, education, and nutritional programs. The most effective interventions lasting 12 months or more included physical activity recommendations, nutrition programs, physical exercise programs, and cooking classes.

For more details, the findings of this review are organized into four categories: the general characteristics of the studies, the assessment of the risk of bias, the main characteristics of the interventions, and the variables studied, as well as the assessment instruments used. Their importance and possible implications are discussed below.

\subsection{General Characteristics of the Studies}

In this review, 12 countries belonging to North America, Europe, and Asia were included, where interventions were developed for the management of obesity in children between 6 and 12 years of age with overweight, or obesity in geographic areas with extremely cold climates. Childhood overweight and obesity are a global problem [1,7], with a higher prevalence in regions where temperatures are lower $[16,18]$. Although $93 \%$ of the studies suffered losses in their sample, the average adherence was very high, $86 \%$, which makes for highly relevant data, since the results of an intervention are dependent on the adherence of its participants. This is in contrast to what some authors state, that dropout at 6 months is close to $40 \%$ [56,57]. This high adherence could be related to the fact that the interventions had a large participation of parents, and that most of them included a behavioral therapy intervention, which is proposed as an effective tool to improve adherence to management programs of childhood obesity [58]. Regarding recruitment, this was carried out mainly from health centers. This could be related to the availability of the records in the health systems of developed countries, which in turn allow better access to potential participants. The main inclusion criterion was BMI (90\%), surpassing other measures that could be more representative of overweight and obesity, such as the percentage of body fat. BMI, even though it is less specific, is the main tool for classifying overweight and obesity, perhaps because it is easy to access and low cost. BMI is the indicator recommended by the WHO to assess anthropometrically the population under 20 years of age, although it is essential to consider the degree of pubertal development before applying it $[59,60] .50 \%$ of the interventions took place in health centers, and only $13 \%$ in educational centers, although educational establishments are the space in which children spend a large part of their time during the day

\subsection{Risk of Bias Assessment}

The distribution of biases classified as "low risk" or "unclear risk" was similar, except for detection bias, which presented a $66 \%$ "unclear" risk. Detection bias is related to the blinding of the assessors to the study results, and although the Cochrane manual states that their blinding does not ensure success, lack of blinding could bias the study results [26]. In any case, the predominant classification of this type of bias, in particular, was "unclear risk" and not "high risk", which is associated with a lack of information regarding this bias on the part of the authors, rather than a possible bias in the results. Besides, although the studies had some "high risk" bias classification, the highest proportion was present in performance bias with $22 \%$, and less than $10 \%$ in the other types of bias. This could be because all the studies have an experimental and randomized methodological design (RCT), which corresponds to the highest level of evidence in terms of quantitative studies. 


\subsection{Main Characteristics of the Interventions}

Most of the studies considered BMI as the main outcome to assess the effects of the interventions. Although this is logical, since it was the main inclusion criterion to classify overweight and obesity, some authors question its use because it is less sensitive to weight change in children with higher body weight [61]. A change in BMI does not necessarily imply a decrease in body fat [62], but it is the indicator recommended by the WHO for anthropometric evaluation in children [59,60]. Most of the studies considered the participation of at least one parent during the intervention. Knowing the role that parents play in the development of obesity in their children, it is of great value that they can actively participate in interventions for its management $[63,64]$. The current gold standard treatment for the management of overweight and obesity in childhood is aimed at both children and parents $[65,66]$, combining components such as physical activity, diet, education, and behavioral therapy [67]. Combined treatment, in addition to nutritional and physical activity intervention, should include behavioral management and education $[68,69]$, to guarantee the maintenance of long-term effects through changes in behavior that promote sustained changes in lifestyle $[58,70]$. The effects of interventions that combine components have been documented both in the short term ( $\leq 6$ months) and in the long term ( $\geq 12$ months) [69,71]. The interventions that lasted 6 months or less presented significant effects in $77 \%$ of cases, and according to the components addressed the modalities that presented greater effectiveness were: in physical activity, recreational activities $(100 \%)$, nutrition and diet program $(100 \%)$, education (100\%) and behavioral therapy (65\%). Regarding the interventions that had a duration of at least 12 months, $89 \%$ presented significant changes in their primary effect, and according to the components addressed the modalities that presented greater effectiveness were: physical activity recommendations $(100 \%)$, the modality of diet programs $(100 \%)$, and the components of education $(92 \%)$ and behavioral therapy $(91 \%)$. It seems that the modality of physical activity recommendations, which consists of recommendations of intensity, time, and frequency, in addition to promoting active transport and reducing sedentary behaviors, has an important effect when the interventions are long-term, but not when the duration of the intervention is less than or equal to 6 months. Regarding the nutrition component, the healthy eating recommendations mode does not have as powerful an effect as the nutrition plans mode. Furthermore, the interventions that include the behavioral therapy component appear not to be as effective when combined with physical activity recommendations and healthy eating recommendations, as opposed to when combined with recreational activities and nutrition plans. It is important to emphasize that the treatment of obesity is not focused only on the reduction of body weight, and it is advisable to do a post-intervention follow-up to maintain the long-term effects [72]. Despite this, only $31 \%$ of the studies considered a post-intervention follow-up evaluation

\subsection{Variables Studied and Assessment Instruments Used}

The nutritional status variables were present in all studies, with BMI being the most studied variable despite its limitations, such as not allowing the distinction between fat mass and lean mass. It has also been observed that some children with normal BMI have fat mass values in the obesity range [73]. Only about $40 \%$ of the studies evaluated body composition through variables other than BMI. To do this, they used doubly indirect methods such as waist circumference and indirect methods such as bioimpedance and DXA, which some authors propose as a better alternative [74]. The physical health variables were considered in $76 \%$ of studies, with the level of physical activity being the most analyzed variable, recorded mainly by indirect methods such as questionnaires, with direct methods such as pedometers and accelerometers rarely used. This could be related to the fact that the physical activity component was approached mainly in the form of physical activity recommendations, rather than with physical exercise programs. Psychological variables were assessed in only $24 \%$ of the studies, with health-related quality of life being the most analyzed variable through questionnaires, surpassing other variables such as depression, anxiety, and self-esteem. Obesity is a disorder of multifactorial origin that affects multiple 
areas of human development, and we believe that the evaluation of psychological variables can provide very relevant data, since children with obesity have a very deteriorated image of themselves, feeling inferior and rejected, which is a drag on their social and psychological development in the short and long term $[75,76]$.

\section{Limitations and Contributions}

A limitation of this study is not having found, in the literature, interventions carried out in other representative countries in areas of extreme cold climate such as Russia, or southern Chile and Argentina. However, studies from 12 countries on three different continents were included, allowing a broad view of the characteristics of interventions to combat childhood overweight and obesity in geographic areas of extreme cold climate. This study can serve as a guide to implement interventions in areas with these characteristics, knowing which ones are the most effective, concerning the components addressed and their duration.

\section{Conclusions}

The interventions that were effective in the management of childhood overweight and obesity were those that combined the components of physical activity, diet, education, and behavioral therapy and that involved both children and their parents as participants in the interventions. In interventions with a duration equal to or less than six months, the most effective included recreational activities, education and nutritional programs. In interventions lasting 12 months or more, the most effective included recommendations for physical activity, nutritional and physical exercise programs, and cooking classes. This demonstrates that the effectiveness of these programs requires a combination of components, with a multi-professional approach, aimed at implementing strategies that favor a healthy lifestyle in children, involving parents as active participants in the process. The results of this review serve as a reference to design future effective interventions in the management of childhood obesity in extremely cold climates.

Author Contributions: J.A.-G. Design, conceptualization of the study, and approval of the final draft. J.A.-G. and R.Z.-L. Design of the search strategy, articles extraction, data analysis, preparation of the figures and/or tables, writing and review of the drafts of the manuscript, and approval of the final draft. S.G., I.C. and G.G.P.d.S. Cross-check of extracted data, review, writing and editing of the manuscript. S.G. and R.Z.-L. Article monitoring. J.A.-G., S.G., I.C., G.G.P.d.S., R.Z.-L. All authors have read and agreed to the published version of the manuscript.

Funding: The authors received no financial support for the research, authorship, and/or publication of this article.

Institutional Review Board Statement: Not applicable.

Informed Consent Statement: Not applicable.

Data Availability Statement: The datasets used and/or analyzed during the current study are avail-able from the corresponding author on reasonable request.

Conflicts of Interest: The authors declared no potential conflicts of interest with respect to the research, authorship, and/or publication of this article.

\section{References}

1. Levesque, R.J.R. Obesity and overweight. In Encyclopedia of Adolescence; Springer: New York, NY, USA, 2011; pp. 1913-1915. [CrossRef]

2. Schattenberg, J.M.; Schuppan, D. Nonalcoholic steatohepatitis: The therapeutic challenge of a global epidemic. Curr. Opin. Lipidol. 2011, 22, 479-488. [CrossRef] [PubMed]

3. Daniels, S.R.; Pratt, C.A.; Hayman, L.L. Reduction of risk for cardiovascular disease in children and adolescents. Circulation 2011, 124, 1673-1686. [CrossRef] [PubMed]

4. O'Rahilly, S. Human obesity and insulin resistance: Lessons from human genetics. Clin. Biochem. 2011, 44, 451. [CrossRef]

5. Renehan, A.G.; Tyson, M.; Egger, M.; Heller, R.F.; Zwahlen, M. Body-mass index and incidence of cancer: A systematic review and meta-analysis of prospective observational studies. Lancet 2008, 371, 569-578. [CrossRef] 
6. Amer, A.; Franchi, L.; Kanneganti, T.D.; Body-Malapel, M.; Özören, N.; Brady, G. Regulation of Legionella phagosome maturation and infection through flagellin and host Ipaf. J. Biol. Chem. 2006, 281, 35217-35223. [CrossRef] [PubMed]

7. Obesity and Overweight. Available online: https://www.who.int/news-room/fact-sheets/detail/obesity-and-overweight (accessed on 17 November 2020).

8. Kesztyüs, D.; Wirt, T.; Kobel, S.; Schreiber, A.; Kettner, S.; Dreyhaupt, J.; Kilian, R.; Steinacker, J.M. Is central obesity associated with poorer health and health-related quality of life in primary school children? Cross-sectional results from the Baden-Württemberg Study. BMC Public Health 2013, 13, 1-11. [CrossRef] [PubMed]

9. Wijga, A.H.; Scholtens, S.; Bemelmans, W.J.; de Jongste, J.C.; Kerkhof, M.; Schipper, M.; Sanders, E.A.; Gerritsen, J.; Brunekreef, B.; Smit, H.A. Comorbidities of obesity in school children: A cross-sectional study in the PIAMA birth cohort. BMC Public Health 2010, 10, 1-10. [CrossRef]

10. Verrotti, A.; Penta, L.; Zenzeri, L.; Agostinelli, S.; De Feo, P. Childhood obesity: Prevention and strategies of intervention. A systematic review of school-based interventions in primary schools. Mol. Diagn. Ther. 2014, 37, 1155-1164. [CrossRef]

11. Reinehr, T. Lifestyle intervention in childhood obesity: Changes and challenges. Nat. Rev. Endocrinol. 2013, 9, 607-614. [CrossRef] [PubMed]

12. Seidell, J.C.; Halberstadt, J. The global burden of obesity and the challenges of prevention. Ann. Nutr. Metab. 2015, 66, 7-12. [CrossRef] [PubMed]

13. Adab, P.; Pallan, M.J.; Lancashire, E.R.; Hemming, K.; Frew, E.; Barrett, T.; Bhopal, R.; Cade, J.E.; Canaway, A.; Clarke, J.L.; et al. Effectiveness of a childhood obesity prevention programme delivered through schools, targeting 6 and 7 year olds: Cluster randomised controlled trial (WAVES study). BMJ 2018, 360, k211. [CrossRef]

14. WHO. Report of the Commission on Ending Childhood Obesity: Implementation Plan: Executive Summary; WHO: Geneva, Switzerland, 2017.

15. Wabitsch, M.; Moss, A.; Kromeyer-Hauschild, K. Unexpected plateauing of childhood obesity rates in developed countries. BMC Med. 2014, 12, 1-5. [CrossRef] [PubMed]

16. Habibzadeh, N. Why Physiologically Cold weather can Increase Obesity Rates? Int. Physiol. J. 2018, 2, 11-13. [CrossRef]

17. Young, T.K. Are the circumpolar inuit becoming obese? Am. J. Hum. Biol. 2007, 19, 181-189. [CrossRef] [PubMed]

18. Morrison, S.F. Central control of body temperature [version 1; referees: 3 approved]. F1000Research 2016, 5. [CrossRef]

19. Braghetto, I.; Taladriz, C.; Lanzarini, E.; Romero, C. Plasma ghrelin levels in the late postoperative period of vertical sleeve gastrectomy. Rev. Med. Chil. 2015, 143, 864-869. [CrossRef] [PubMed]

20. Anon. n.d. Top 15 Coldest Countries in the World 2020. Available online: https:// earthnworld.com/coldest-countries-in-theworld/ (accessed on 17 November 2020).

21. Köppen, W. Versuch einer Klassifikation der Klimate, vorzugsweise nach ihren Beziehungen zur Pflanzenwelt (Examination of a climate classification preferably according to its relation to the flora). Geogr. Zeitschr. 1900, 6, 593-611, 657-679.

22. Sarricolea, P.; Herrera-Ossandon, M.; Meseguer-Ruiz, Ó. Climatic regionalisation of continental Chile. J. Maps 2017, 13, 66-73. [CrossRef]

23. Santana, A.; Butorovic, N.; Olave, C. Variación de la temperatura en punta arenas (chile) en los últimos 120 años. An. del Inst. la Patagon. 2009, 37, 85-96. [CrossRef]

24. Liberati, A.; Altman, D.G.; Tetzlaff, J.; Mulrow, C.; Gøtzsche, P.C.; Ioannidis, J.P.; Clarke, M.; Devereaux, P.J.; Kleijnen, J.; Moher, D. The PRISMA statement for reporting systematic reviews and meta-analyses of studies that evaluate health care interventions: Explanation and elaboration. J. Clin. Epidemiol. 2009, 62, e1-e34. [CrossRef] [PubMed]

25. McGowan, J.; Sampson, M.; Salzwedel, D.M.; Cogo, E.; Foerster, V.; Lefebvre, C. PRESS Peer Review of Electronic Search Strategies: 2015 Guideline Statement. J. Clin. Epidemiol. 2016, 75, 40-46. [CrossRef]

26. Shuster, J.J. Review: Cochrane handbook for systematic reviews for interventions, Version 5.1.0, published 3/2011. Julian, P.T. Higgins and Sally Green, Editors. Res. Synth. Methods 2011, 2, 126-130. [CrossRef]

27. Marild, S.; Gronowitz, E.; Forsell, C.; Dahlgren, J.; Friberg, P. A controlled study of lifestyle treatment in primary care for children with obesity. Pediatr. Obes. 2013, 8, 207-217. [CrossRef]

28. Cohen, T.R.; Hazell, T.J.; Vanstone, C.A.; Rodd, C.; Weiler, H.A. A family-centered lifestyle intervention for obese six-to eightyear-old children: Results from a one-year randomized controlled trial conducted in Montreal, Canada. Can. J. Public Health 2016, 107, e453-e460. [CrossRef] [PubMed]

29. Larsen, K.T.; Huang, T.; Ried-Larsen, M.; Andersen, L.B.; Heidemann, M.; Møller, N.C. A multi-component day-camp weight-loss program is effective in reducing bmi in children after one year: A randomized controlled trial. PLoS ONE 2016, 11, e0157182. [CrossRef] [PubMed]

30. Saelens, B.E.; Lozano, P.; Scholz, K. A randomized clinical trial comparing delivery of behavioral pediatric obesity treatment using standard and enhanced motivational approaches. J. Pediatr. Psychol. 2013, 38, 954-964. [CrossRef]

31. Gunnarsdottir, T.; Sigurdardottir, Z.G.; Njardvik, U.; Olafsdottir, A.S.; Bjarnason, R. A randomized-controlled pilot study of Epstein's family-based behavioural treatment for childhood obesity in a clinical setting in Iceland. Nord. Psychol. 2011, 63, 6-19. [CrossRef]

32. Harder-Lauridsen, N.M.; Birk, N.M.; Ried-Larsen, M.; Juul, A.; Andersen, L.B.; Pedersen, B.K.; Krogh-Madsen, R. A randomized controlled trial on a multicomponent intervention for overweight school-aged children-Copenhagen, Denmark. BMC Pediatr. 2014, 14, 1-14. [CrossRef] 
33. Reinehr, T.; Schaefer, A.; Winkel, K.; Finne, E.; Toschke, A.M.; Kolip, P. An effective lifestyle intervention in overweight children: Findings from a randomized controlled trial on 'Obeldicks light'. Clin. Nutr. 2010, 29, 331-336. [CrossRef]

34. Benestad, B.; Lekhal, S.; Småstuen, M.C.; Hertel, J.K.; Halsteinli, V.; Ødegård, R.A.; Hjelmesæth, J. Camp-based family treatment of childhood obesity: Randomised controlled trial. Arch. Dis. Child. 2017, 102, 303-310. [CrossRef] [PubMed]

35. Danielsson, P.; Bohlin, A.; Bendito, A.; Svensson, A.; Klaesson, S. Five-year outpatient programme that provided children with continuous behavioural obesity treatment enjoyed high success rate. Acta Paediatr. Int. J. Paediatr. 2016, 105, 1181-1190. [CrossRef]

36. Epstein, L.H.; Paluch, R.A.; Wrotniak, B.H.; Daniel, T.O.; Kilanowski, C.; Wilfley, D.; Finkelstein, E. Cost-effectiveness of family-based group treatment for child and parental obesity. Child. Obes. 2014, 10, 114-121. [CrossRef] [PubMed]

37. Wilfley, D.E.; Saelens, B.E.; Stein, R.I.; Best, J.R.; Kolko, R.P.; Schechtman, K.B.; Wallendorf, M.; Welch, R.R.; Perri, M.G.; Epstein, L.H. Dose, content, and mediators of family-based treatment for childhood obesity a multisite randomized clinical trial. JAMA Pediatr. 2017, 171, 1151-1159. [CrossRef]

38. Larsen, L.M.; Hertel, N.T.; Mølgaard, C.; Christensen, R.D.; Husby, S.; Jarbøl, D.E. Early intervention for childhood overweight: A randomized trial in general practice. Scand. J. Prim. Health Care 2015, 33, 184-190. [CrossRef] [PubMed]

39. Farpour-Lambert, N.J.; Martin, X.E.; Bucher Della Torre, S.; Von Haller, L.; Ells, L.J.; Herrmann, F.R.; Aggoun, Y. Effectiveness of individual and group programmes to treat obesity and reduce cardiovascular disease risk factors in pre-pubertal children. Clin. Obes. 2019, 9, e12335. [CrossRef]

40. Wylie-Rosett, J.; Groisman-Perelstein, A.E.; Diamantis, P.M.; Jimenez, C.C.; Shankar, V.; Conlon, B.A.; Mossavar-Rahmani, Y.; Isasi, C.R.; Martin, S.N.; Ginsberg, M.; et al. Embedding weight management into safety-net pediatric primary care: Randomized controlled trial. Int. J. Behav. Nutr. Phys. 2018, 15, 1-12. [CrossRef]

41. Warschburger, P.; Kroeller, K.; Haerting, J.; Unverzagt, S.; van Egmond-Fröhlich, A. Empowering Parents of Obese Children (EPOC): A randomized controlled trial on additional long-term weight effects of parent training. Appetite 2016, 103, 148-156. [CrossRef] [PubMed]

42. Christison, A.L.; Evans, T.A.; Bleess, B.B.; Wang, H.; Aldag, J.C.; Binns, H.J. Exergaming for Health: A Randomized Study of Community-Based Exergaming Curriculum in Pediatric Weight Management. Games Health J. 2016, 5, 413-421. [CrossRef] [PubMed]

43. Croker, H.; Viner, R.M.; Nicholls, D.; Haroun, D.; Chadwick, P.; Edwards, C.; Wells, J.C.; Wardle, J. Family-based behavioural treatment of childhood obesity in a UK national health service setting: Randomized controlled trial. Int. J. Obes. 2012, 36, 16-26. [CrossRef] [PubMed]

44. Kokkvoll, A.; Grimsgaard, S.; Steinsbekk, S.; Flægstad, T.; Njølstad, I. Health in overweight children: 2-Year follow-up of Finnmark Activity School-A randomised trial. Arch. Dis. Child. 2015, 100, 441-448. [CrossRef] [PubMed]

45. Doyle-Baker, P.K.; Venner, A.A.; Lyon, M.E.; Fung, T. Impact of a combined diet and progressive exercise intervention for overweight and obese children: The BEHIP study. Appl. Physiol. Nutr. Metab. 2011, 36, 515-525. [CrossRef]

46. Kalavainen, M.P.; Korppi, M.O.; Nuutinen, O.M. Clinical efficacy of group-based treatment for childhood obesity compared with routinely given individual counseling. Int. J. Obes. 2007, 31, 1500-1508. [CrossRef]

47. Njardvik, U.; Gunnarsdottir, T.; Olafsdottir, A.S.; Craighead, L.W.; Boles, R.E.; Bjarnason, R. Incorporating appetite awareness training within family-based behavioral treatment of pediatric obesity: A randomized controlled pilot study. J. Pediatr. Psychol. 2018, 43, 1017-1027. [CrossRef] [PubMed]

48. Gerards, S.M.; Dagnelie, P.C.; Gubbels, J.S.; Van Buuren, S.; Hamers, F.J.; Jansen, M.W.; Van Der Goot, O.H.; De Vries, N.K.; Sanders, M.R.; Kremers, S.P. The effectiveness of lifestyle triple P in the Netherlands: A randomized controlled trial. PLoS ONE 2015, 10, e0122240. [CrossRef] [PubMed]

49. Boutelle, K.N.; Cafri, G.; Crow, S.J. Parent-only treatment for childhood obesity: A randomized controlled trial. Obesity 2011, 19, 574-580. [CrossRef] [PubMed]

50. Robertson, W.; Fleming, J.; Kamal, A.; Hamborg, T.; A Khan, K.; Griffiths, F.; Stewart-Brown, S.; Stallard, N.; Petrou, S.; Simkiss, D.; et al. Randomised controlled trial and economic evaluation of the 'Families for Health' programme to reduce obesity in children. Arch. Dis. Child. 2017, 102, 416-426. [CrossRef] [PubMed]

51. Hao, M.; Han, W.; Yamauchi, T. Short-Term and Long-Term Effects of a Combined Intervention of Rope Skipping and Nutrition Education for Overweight Children in Northeast China. Asia-Pac. J. Public Health 2019, 31, 348-358. [CrossRef]

52. Stovitz, S.D.; Berge, J.M.; Wetzsteon, R.J.; Sherwood, N.E.; Hannan, P.J.; Himes, J.H. Stage 1 treatment of pediatric overweight and obesity: A pilot and feasibility randomized controlled trial. Child. Obes. 2014, 10, 50-57. [CrossRef] [PubMed]

53. de Niet, J.; Timman, R.; Bauer, S.; van den Akker, E.; Buijks, H.; de Klerk, C.; Kordy, H.; Passchier, J. The effect of a short message service maintenance treatment on body mass index and psychological well-being in overweight and obese children: A randomized controlled trial. Pediatr. Obes. 2012, 7, 205-219. [CrossRef]

54. Sherwood, N.E.; Levy, R.L.; Seburg, E.M.; Crain, A.L.; Langer, S.L.; JaKa, M.M.; Kunin-Batson, A.; Jeffery, R.W. The Healthy Homes/Healthy Kids 5-10 Obesity Prevention Trial: 12 and 24-month outcomes. Pediatr. Obes. 2019, 14, e12523. [CrossRef]

55. Saelens, B.E.; Scholz, K.; Walters, K.; Simoni, J.M.; Wright, D.R. Two Pilot Randomized Trials to Examine Feasibility and Impact of Treated Parents as Peer Interventionists in Family-Based Pediatric Weight Management. Child. Obes. 2017, 13, 314-323. [CrossRef] [PubMed]

56. Summerbell, C.D.; Ashton, V.; Campbell, K.J.; Edmunds, L.; Kelly, S.; Waters, E. Interventions for treating obesity in children. In Cochrane Database of Systematic Reviews; John Wiley \& Sons, Inc.: Hoboken, NJ, USA, 2003. [CrossRef] 
57. Zeller, M.; Kirk, S.; Claytor, R.; Khoury, P.; Grieme, J.; Santangelo, M.; Daniels, S. Predictors of attrition from a pediatric weight management program. J. Pediatr. 2004, 144, 466-470. [CrossRef] [PubMed]

58. Braet, C.; Van Winckel, M.; Van Leeuwen, K. Follow-up results of different treatment programs for obese children. Acta Paediatr. Int. J. Paediatr. 1997, 86, 397-402.

59. Pietrobelli, A.; Faith, M.S.; Allison, D.B.; Gallagher, D.; Chiumello, G.; Heymsfield, S.B. Body mass index as a measure of adiposity among children and adolescents: A validation study. J. Pediatr. 1998, 132, 204-210. [CrossRef]

60. Burrows, R.; Díaz, N.; Muzzo, S. Variaciones del índice de masa corporal (IMC) de acuerdo al grado de desarrollo puberal alcanzado. Rev. Med. Chile 2004, 132, 1363-1368. [CrossRef] [PubMed]

61. Cole, T.J.; Faith, M.S.; Pietrobelli, A.; Heo, M. What is the best measure of adiposity change in growing children: BMI, BMI \%, BMI z-score or BMI centile? Eur. J. Clin. Nutr. 2005, 59, 419-425. [CrossRef] [PubMed]

62. Neovius, M.G.; Linné, Y.M.; Barkeling, B.S.; Rossner, S.O. Sensitivity and specificity of classification systems for fatness in adolescents. Am. J. Clin. Nutr. 2004, 80, 597-603. [CrossRef]

63. Epstein, L.H.; McCurley, J.; Wing, R.R.; Valoski, A. Five-year follow-up of family-based behavioral treatments for childhood obesity. J. Consult. Clin. Psychol. 1990, 58, 661-664. [CrossRef]

64. Kitzmann, K.M.; Beech, B.M. Family-based interventions for pediatric obesity: Methodological and conceptual challenges from family psychology. J. Fam. Psychol. 2006, 20, 175-189. [CrossRef] [PubMed]

65. Epstein, L.H.; Valoski, A.; Wing, R.R.; McCurley, J. Ten-year outcomes of behavioral family-based treatment for childhood obesity. Health Psychol. 1994, 13, 373-383. [CrossRef]

66. Wrotniak, B.H.; Epstein, L.H.; Paluch, R.A.; Roemmich, J.N. Parent Weight Change as a Predictor of Child Weight Change in Family-Based Behavioral Obesity Treatment. Arch. Pediatr. Adolesc. Med. 2004, 158, 342-347. [CrossRef] [PubMed]

67. Epstein, L.H. Family-based behavioural intervention for obese children. Int. J. Obes. 1996, 20, S14-S21.

68. Luttikhuis, H.O.; Baur, L.; Jansen, H.; Shrewsbury, V.A.; O’Malley, C.; Stolk, R.P.; Summerbell, C.D. Interventions for treating obesity in children. Cochrane Database Syst. Rev. 2009. [CrossRef]

69. Nemet, D.; Barkan, S.; Epstein, Y.; Friedland, O.; Kowen, G.; Eliakim, A. Short- and long-term beneficial effects of a combined dietary-behavioral- physical activity intervention for the treatment of childhood obesity. Pediatrics 2005, 115, e443-e449. [CrossRef] [PubMed]

70. Epstein, L.H.; Roemmich, J.N.; Raynor, H.A. Behavioral therapy in the treatment of pediatric obesity. Pediatr. Clin. N. Am. 2001, 48, 981-993. [CrossRef]

71. Kain, J.; Vio, F.; Leyton, B.; Cerda, R.; Olivares, S.; Uauy, R.; Albala, C. Estrategia de promoción de la salud en escolares de educación básica municipalizada de la comuna de casablanca, chile. Rev. Chil. Nutr. 2005, 32, 126-132. [CrossRef]

72. García-Reyna, N.I.; Gussinyer, S.; Carrascosa, A. Niñ@s en Movimiento, un programa para el tratamiento de la obesidad infantil. Med. Clin. 2007, 129, 619-623. [CrossRef] [PubMed]

73. Chueca, M.; Azcona, C.; Oyarzábal, M. Obesidad infantil Childhood obesity. An. Sis San Navar. 2002, 25, 127-141.

74. Elia, M.; Ward, L.C. New techniques in nutritional assessment: Body composition methods. Proc. Nutr. Soc. 1999, 58, 33-38. [CrossRef] [PubMed]

75. Gortmaker, S.L.; Must, A.; Perrin, J.M.; Sobol, A.M.; Dietz, W.H. Social and economic consequences of overweight in adolescence and young adulthood. Eur. J. Pediatr. 1994, 153, 207. [CrossRef] [PubMed]

76. Nansel, T.R.; Overpeck, M.; Pilla, R.S.; Ruan, W.J.; Simons-Morton, B.; Scheidt, P. Bullying behaviors among US youth: Prevalence and association with psychosocial adjustment. J. Am. Med. Assoc. 2001, 285, 2094-2100. [CrossRef] [PubMed] 